\section{Recurrent haemoptysis in a young woman: a case of a malignant haemangiopericytoma of the lung}

\author{
T B Rothe, W Karrer, J-O Gebbers
}

\begin{abstract}
A 36 year old woman presented with mild recurrent haemoptysis and cough persisting over several months caused by a malignant haemangiopericytoma of the right lung.
\end{abstract}

(Thorax 1994;49:188-189)

Haemangiopericytomas were first described by Stout and Murray. ${ }^{1}$ About half occur at a musculoskeletal site and a primary pulmonary location is rare. To date about 90 cases of pulmonary origin have been published, most of them having been compiled in two reviews. ${ }^{23}$ The degree of malignancy seems to be higher when the tumour is located in the lung.

We present a case of a malignant haemangiopericytoma in a young woman, and a short review of the current literature to stress the importance of an accurate diagnosis and the potential malignancy of this neoplasm.

\section{Case report}

The 36 year old non-smoking woman had noticed a dry cough and minimal haemoptysis since November 1989. Three months later she became febrile and a chest radiograph revealed inhomogeneous consolidation of the right upper lobe. After treatment with antibiotics the fever ceased, but the cough and haemoptysis persisted. In March 1990 acid-fast mycobacteria had grown in one sputum culture. Antituberculous chemotherapy was started and the patient was admitted to hospital.

A second radiograph revealed a round, sharply defined mass $8 \mathrm{~cm}$ in diameter in the right upper lobe (fig 1). Bronchoscopic examination showed that the tumour was blocking the apical segment of the right upper lobe. Histological examination of biopsy samples yielded neoplastic tissue with small round and spindle shaped cells.

The tumour was removed by pneumonectomy in May 1990. In October 1990 the patient suddenly died. At necropsy massive thrombotic embolism of the left lung was present as well as a solid metastasis weighing $290 \mathrm{~g}$ at the base of the pneumonectomy cavity. Non-pathogenic mycobacteria were identified from the sputum culture.
PATHOLOGICAL FINDINGS

The pneumonectomy specimen included a lobated $8 \mathrm{~cm}$ tumour infiltrating the upper lobe bronchus. Macroscopically, the pleura was intact. The tumour had a typical light microscopic appearance of a vascular pattern with small, thin walled, branched sinusoidal spaces between solid cellular areas. Reticulin and collagen fibres enmeshed the tumour cells (fig 2). Twenty five to 33 mitotic figures were found per 10 high power fields. Several necrotic areas were located within the tumour and, at its margin, infiltration into the lung parenchyma and the visceral pleura was present.

Immunohistochemically a strongly positive reaction was found in the frozen sections for vimentin in all cells, and for factor VIIIrelated antigen in the cells lining the sinusoidal spaces. Both these findings are typical of haemangiopericytoma. ${ }^{4}$ The immunohistochemical reaction with the proliferation marker $\mathrm{Ki}-67^{5}$ was positive in $15-20 \%$ of the tumour cells indicating a high proliferative activity. Reactions for cytokeratins, neuron-specific enolase, desmin, actin, and S-100 protein were negative.

No other pathological lesions were found in the lung. Mycobacteria could not be detected histologically.

\section{Discussion}

The histogenesis of haemangiopericytoma is controversial ${ }^{46}$ but, because of its light microscopical, ultrastructural, and immunohistochemical features, most clinicians favour an origin from pericytes around the small blood vessels. It is an uncommon neoplasm, particularly in the lung. The tumours can be central or peripheral.

In two of the 18 cases from the largest series described by Yousem and Hochholzer an endobronchial polypoid lesion was found. ${ }^{3}$ Pleural infiltration was noted in eight cases, areas of necrosis in 15, and vascular invasion in seven. Metastases to regional lymph nodes or to distant sites were not detected at the time of thoracotomy. Mitotic figures were absent in two cases and in the other 16 specimens 3-43 mitotic figures per 10 high power fields were found.

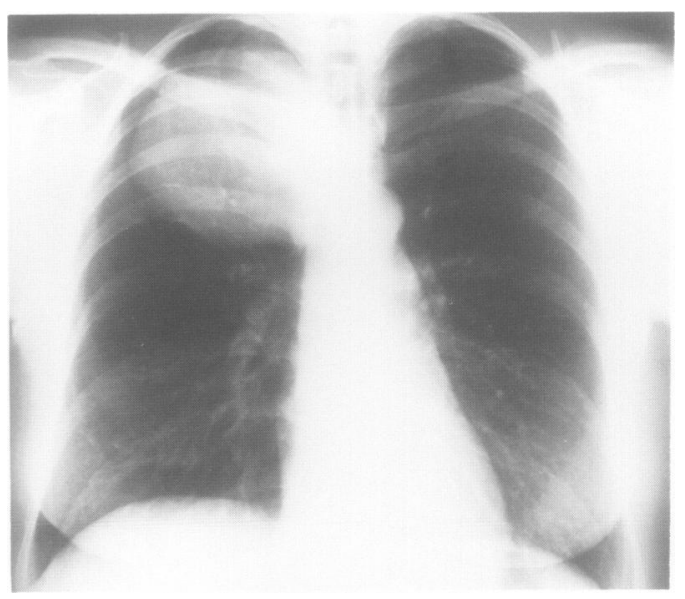

Figure 1 Radiograph of the thorax with an $8 \mathrm{~cm}$ diameter tumour in the right upper field. 


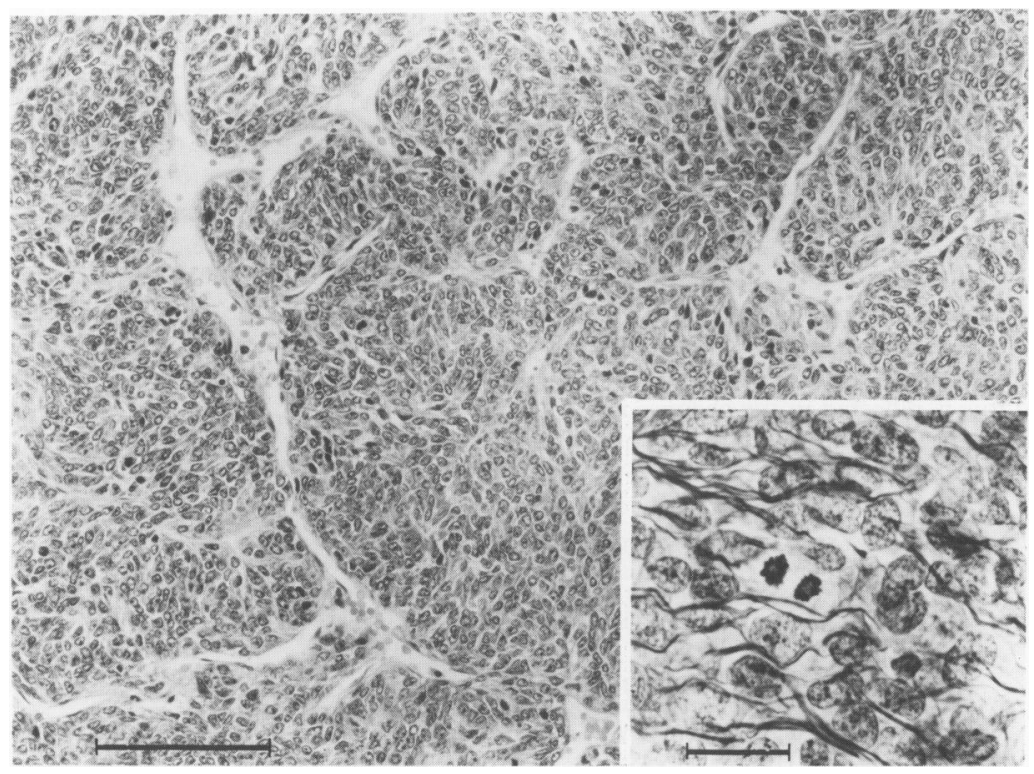

Figure 2 Photomicrograph of the malignant haemangiopericytoma featuring the high cellularity of the neoplasm and the branching vascular channels with staghorn configuration. Haematoxylin and eosin. Bar $=100 \mu \mathrm{m}$. Inset: Reticulin fibres form a typical network around single cells or around small cell groups. Gomori silver impregnation. Bar $=20 \mu \mathrm{m}$.
There is no radiological feature to help distinguish this neoplasm from others. ${ }^{7}$ A computed tomographic scan during follow up of our case might have shown the metastasis sooner. ${ }^{8}$ Better results in evaluation of the postpneumonectomy space are reported by magnetic resonance imaging.

The main therapeutic approach to haemangiopericytomas is wide surgical resection. Postoperative radiotherapy may be of value. ${ }^{9}$ In cases of potential malignancy according to the criteria of Yousem and Hochholzer mentioned above, a supplementary irradiation might improve the prognosis.

Chemotherapy is restricted to metastasising haemangiopericytomas when some palliation of advanced disease may be achieved. ${ }^{10}$

1 Stout AP, Murray MR. Hemangiopericytoma: a vascular tumor featuring Zimmermann's pericytes. Ann Surg 1942;166:26-33.

2 Shin MS, Ho KJ. Primary hemangiopericytoma of lung. AFR 1979;133:1077-83.

3 Yousem SA, Hochholzer L. Primary pulmonary hemangiopericytoma. Cancer 1987;59:549-55.

4 Nemes Z. Differentiation markers in hemangiopericytoma. Cancer 1992;69:133-40.

5 Schwerting R, Gerdes J, Niehus J, Jaeschke H, Stein H. Determination of the growth fraction in cell suspensions by flow cytometry using the monoclonal antibody $\mathrm{Ki}-67$. f Immunol Methods 1986;90:65-70.

6 Poerter PL, Gigler SA, Gown AM. The immunophenotype of hemangiopericytomas and glomus tumors, with special reference to muscle protein expression. Modern Pathol 1991;4:46-52.

7 Alpern MB, Thorsen K, Kellman GM, Pojunas K, Lawson G. CT appearance of hemangiopericytoma. $\mathcal{f}$ Comput Assist Tomogr 1986;10:264-7.

proposed and malignant - according to the following criteria: (1) infiltration of the chest wall or mediastinum; (2) histological proof of angiolymphatic invasion; and (3) metastasis or recurrence of the tumour. Additional adverse prognostic factors include size greater than $8 \mathrm{~cm}$ diameter, necrosis, and mitotic rate greater than three per 10 high power fields.
Biondetti PR, Fiore D, Sartori F, Colognato A, Ravasini R, Romani $S$. Evaluation of the post-pneumonectomy space by CT. F Comput Assist Tomogr 1982;6:238-42. erapy have a role in hemangiopericytoma management? Int f Radiat Oncol Biol Phys 1987;13:1399-402.

10 Beadle GF, Hillcoat BL. Treatment of advanced malignant hemangiopericytoma with combination adriamycin and 70 .
9 Iha N, McNeese M, Barkley Jr HT, Kong J. Does radioth- 